\title{
Ionospheric slab thickness and its seasonal variations observed by GPS
}

\author{
Shuanggen Jin*, Jung-Ho Cho, Jung-Uk Park \\ Space Geodesy Division, Korea Astronomy and Space Science Institute, 61-1, Whaam-dong, Yusong-gu, Daejeon 305-348, South Korea
}

Received 9 April 2007; received in revised form 20 July 2007; accepted 27 July 2007

Available online 3 August 2007

\begin{abstract}
The ionospheric slab thickness, the ratio of the total electron content (TEC) to the F2-layer peak electron density $(\mathrm{NmF} 2)$, is closely related to the shape of the ionospheric electron density profile $\mathrm{Ne}(h)$ and the TEC. Therefore, the ionospheric slab thickness is a significant parameter representative of the ionosphere. In this paper, the continuous GPS observations in South Korea are firstly used to study the equivalent slab thickness (EST) and its seasonal variability. The averaged diurnal medians of December-January-February (DJF), March-April-May (MAM), June-July-August (JJA) and September-October-November (SON) in 2003 have been considered to represent the winter, spring, summer and autumn seasons, respectively. The results show that the systematic diurnal changes of TEC, NmF2 and EST significantly appeared in each season and the higher values of TEC and NmF2 are observed during the equinoxes (semiannual anomaly) as well as in the mid-daytime of each season. The EST is significantly smaller in winter than in summer, but with a consistent variation pattern. During 14-16 LT in daytime, the larger EST values are observed in spring and autumn, while the smaller ones are in summer and winter. The peaks of EST diurnal variation are around 10-18 LT which are probably caused by the action of the thermospheric wind and the plasmapheric flow into the F2-region.

(C) 2007 Elsevier Ltd. All rights reserved.
\end{abstract}

Keywords: Ionospheric slab thickness; GPS; TEC; South Korea

\section{Introduction}

The ionospheric slab thickness is defined as the ratio of the total electron content (TEC) to the maximum electron density of the F-region $(\mathrm{NmF} 2$, proportional to the square of the F2-layer critical frequency foF2). It represents the equivalent slab thickness (EST) of the ionosphere having a constant

\footnotetext{
${ }^{*}$ Corresponding author. Tel.: + 82428653241 ; fax: +82428615610 .

E-mail addresses: sgjin@kasi.re.kr,sg.jin@yahoo.com (S. Jin).
}

uniform density of the F2 peak. The EST has a great influence on the shape of the ionospheric electron density profile $\mathrm{Ne}(h)$, and is also a convenient oneparameter summary of the electron density profile that may be related to the various physical processes. The ionospheric slab thickness is thus very helpful in understanding the nature of variations of the upper atmosphere and is therefore employed in modelling the ionosphere, such as the International Reference Ionosphere (IRI) (Bilitza, 2001). In addition, for a Chapman layer, Wright (1960) showed that the value of EST is equal to $4.13 H$, where $H$ is the scale height of the ionosphere. 
Furman and Prasad (1973) further testified that EST generally depends upon the plasma scale height. Moreover, Titheridge (1973) has found a relationship between EST and neutral temperature. Therefore, the EST contains information regarding the neutral temperature and, for an assumed electron density profile, can be related directly to the scale height of the ionizable parameters. Besides, the EST is a useful parameter in satellite-to-ground radio communication as the relations between the EST and the F2-layer peak electron density NmF2 can provide an estimate of TEC and the refraction and rotation of electric field of the radio wave.

Therefore, the EST is capable of addressing many useful ionospheric parameters and a study of this parameter at any location provides information about the nature of the distribution of ionization. Over the last five decades, a number of studies have been performed on the variation of this parameter under different geophysical conditions (e.g. Bhonsle et al., 1965; Kersley and Hajeb Hosseinieh, 1976; Huang, 1983; Davies and Liu, 1991; Minakoshi and Nishimuta, 1994; Gulyaeva, 1997). However, in the past, the EST and its variability were generally studied with several independent data, such as the TEC from the GOES satellite and the foF2 from the ionosonde (Jaychandran et al., 2004; Mansilla et al., 2005), or with other expensive techniques, such as incoherent scatter radar (Pandey et al., 2001). It may induce unreliable estimations in EST as each observation technique has its own feature and representative. In this paper, the EST and its seasonal variation are first studied from the most low-cost and convenient GPS observations in South Korea. In the following sections, the method of imaging a 3-D ionospheric structure is addressed in brief. Results and discussions are given in Section 3 as well as the conclusion in the final section.

\section{Observations and methods}

The Korean GPS Network (KGN) with $\sim 50$ permanent GPS sites has been established since 2000 by the Korea Astronomy and Space Science Institute (KASI), Ministry Of Governmental Administration and Home Affairs (MOGAHA), National Geographic Information Institute (NGII), etc. The spatial resolution of GPS network is about $20-50 \mathrm{~km}$, which provides high spatial-resolution observations. Since the ionosphere is a dispersive medium, dual-frequency GPS receivers $(f 1=1575.42$ and $f 2=1227.60 \mathrm{MHz})$ are able to estimate the ionospheric effect with measurements of the modulations on the GPS codes and the carrier phases. The equations of carrier phase $(L)$ and code observations (pseudorange $P$ ) of double-frequency GPS can be expressed as follows:

$L_{k, j}^{i}=\lambda_{k} \phi_{k, j}^{i}=\rho_{0, j}^{i}-d_{\mathrm{ion}, k_{,}}^{i}+d_{\mathrm{trop}, j}^{i}+c\left(\tau^{i}-\tau_{j}\right)-\lambda_{k}\left(b_{k, j}^{i}+N_{k, j}^{i}\right)$,

$P_{k, j}^{i}=\rho_{0, j}^{i}+d_{\text {ion }, k, j}^{i}+d_{\text {trop }, j}^{i}+c\left(\tau^{i}-\tau_{j}\right)+d_{q, k}^{i}+d_{q, k, j}+\varepsilon_{j}^{i}$,

where superscript $i$ and subscript $j$ represent the satellite and ground-based GPS receiver, respectively, $k(=1,2)$ is the frequency, $\rho_{0}$ is the true distance between the GPS receiver and satellite, $d_{\text {ion }}$ and $d_{\text {trop }}$ are the ionospheric and tropospheric delays, respectively, $c$ is the speed of light in vacuum space, $\tau$ is the satellite or receiver clock offset, $b$ is the phase delay of satellite and receiver instrument bias, $d_{\mathrm{q}}$ is the code delay of satellite and receiver instrumental bias, $\lambda$ is the carrier wavelength, $\phi$ is the total carrier phase between the satellite and receiver, $N$ is the ambiguity of the carrier phase, and $\varepsilon$ denotes other residuals. After considering all kinds of possible bias and errors, such as instrument bias and clock errors, the precise slant TEC (STEC) of a ray path can be derived from continuous dualfrequency GPS observations. The STEC is defined as the line integral of the electron density:

$\mathrm{STEC}=\int_{R_{\text {receiver }}}^{R_{\text {satellite }}} N_{\mathrm{e}}(\lambda, \varphi, h) \mathrm{d} s$,

where $N_{\mathrm{e}}(\lambda, \varphi, h)$ is the ionospheric electron density, $\lambda, \varphi$ and $h$ are the longitude, latitude and height, respectively. With the STEC of all ray paths, the 3D ionospheric electron density profiles can be produced through a tomography reconstruction algorithm, here using the multiplicative algebraic reconstruction technique (MART) (Raymund et al., 1990). The tomography reconstruction algorithm can integrate the data from all available GPS receivers and all GPS satellites visible from each of these receivers above a user-specified elevation cut-off angle (usually $15^{\circ}$ ). The unknown electron density profile is expressed in 4-D (longitudelatitude-height and time) voxel basis functions over the following grid: longitude $124-130^{\circ}$ in $1^{\circ}$ increments, latitude $33-39^{\circ}$ in $0.5^{\circ}$ increments, altitude $100-1000 \mathrm{~km}$ in $25 \mathrm{~km}$ increments and time: $1 \mathrm{~h}$ increments of linear change in the electron density per voxel. Note, here we only consider the ionosphere altitude $1000 \mathrm{~km}$ due to very sparser ions over $1000 \mathrm{~km}$, and therefore over $1000 \mathrm{~km}$ effects on the ionospheric electron density profile inversion are 
very small. Furthermore, it is fast to inverse the unknown ionospheric density parameters because of reduced unknown variables. Each set of STEC measurements along the ray paths from all observable satellites and from consecutive epochs are combined with the ray path geometry into a linear expression:

$Y=A x+\varepsilon$,

where $A$ is a matrix relating the ray paths to the voxels, $Y$ is a column vector containing the observed STEC values, $x$ is the column vector of unknown coefficients of the basis functions and $\varepsilon$ is the residual. The inversion of this matrix gives the unknown coefficients of the electron density distribution from which the vertical electron density or vertical TEC at any location can be inferred. The solution is constrained using a priori information from the IRI-2001 or ionosonde. For more details about the reconstruction algorithm, the reader can refer to Gordon et al. (1970) and Raymund et al. (1990). Here, the priori information uses the ionosonde observations at Anyang station $\left(37.39^{\circ} \mathrm{N}, 126.95^{\circ} \mathrm{E}\right)$ in South Korea. The validity is further verified by comprising the ground-based GPS tomographically reconstructed electron density profiles with the independent ionosonde observations. For more details about the reconstruction algorithm, the reader is referred to Jin et al. (2006) and Jin and Park (2007).

Once the TEC and maximum electron density $\mathrm{NmF} 2$ are extracted from GPS measurements, the EST $\tau$, in $\mathrm{km}$, for each hour is computed from the following relation:

$\tau=\mathrm{TEC} / \mathrm{NmF} 2$,

where $\mathrm{NmF} 2$ is the maximum electron density of the F-region in $\mathrm{el} \mathrm{m}^{-3}$. The EST is then obtained as a function of the local time at intervals of $1 \mathrm{~h}$ for each day separately. The averaged diurnal medians for December-January-February (DJF), MarchApril-May (MAM), June-July-August (JJA) and September-October-November (SON) in 2003 have been considered to represent the winter, spring, summer and autumn seasons, respectively. Here some days with no or bad observation data are not used.

\section{Results and discussion}

Ionospheric electron density profiles are obtained by the GPS tomography reconstruction technique.
Then, we conduct the electron density deviation analysis of GPS ionospheric reconstruction and ionosonde observation with respect to the IRI-2001 model. A good ionospheric reconstruction electron density profile $N_{\text {reconstruction }}(\lambda, \varphi, t)$ should give a good electron density peak $N_{\text {max }}$. To assess the quality, a simple deviation percentage can be defined as follows:

$$
\begin{aligned}
D N_{\max }(\varphi, \lambda, t)=[ & \left(N_{\max }\left(N_{1}(\varphi, \lambda, t)\right)\right. \\
& \left.\left.-N_{\max }\left(N_{2}(\varphi, \lambda, t)\right)\right) / N_{\max }\left(N_{2}(\varphi, \lambda, t)\right)\right] \times 100 \%,
\end{aligned}
$$

where $N_{1}$ and $N_{2}$ are the electron density profiles of the GPS-reconstructed $N_{\text {GPS-reconstruction }}$ and the IRI 2001-estimated $N_{\text {IRI-2001, }}$, respectively, $N_{\max }$ is the electron density peak, and $D N_{\max }(\varphi, \lambda, t)$ is the deviation percentage value of maximum GPSreconstructed ionospheric electron density with respect to the IRI-2001 estimation. The averaged diurnal percentage variations of the seasonal median $\left(\overline{D N_{\max }}\right)$ can be obtained, comprising peak density deviation percentages as calculated from GPS reconstruction and ionosonde with respect to the IRI-2001 over the Anyang ionosonde station $\left(37.39^{\circ} \mathrm{N}, 126.95^{\circ} \mathrm{E}\right)$ in 2003 . It has been shown that the deviation percentages of electron peak densities from GPS reconstruction are in good agreement with the ionosonde in four seasons, but have systematic deviations with the IRI-2001 model.

In order to check the validity of the IRI-2001 for predicting the seasonal variation of $\mathrm{NmF} 2$, the

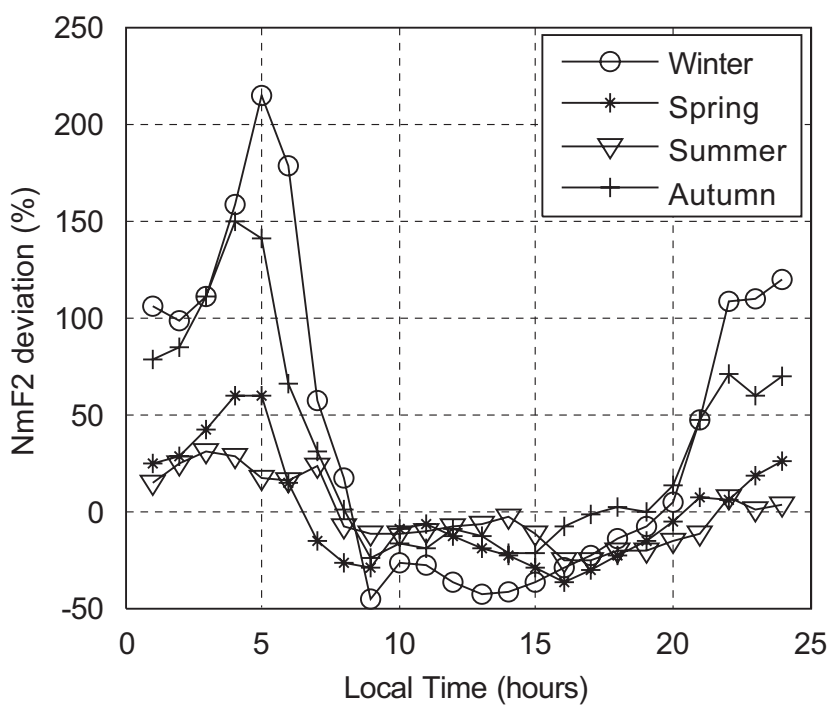

Fig. 1. Averaged diurnal variations of the seasonal median of the relative deviations of GPS-reconstructed $\mathrm{NmF} 2$ with respect to the IRI-2001 model. 
diurnal variations DNmF2 of GPS reconstruction with respect to the IRI-2001 model are compared in winter, spring, summer and autumn as shown in Fig. 1. It has been seen that the IRI-2001 model significantly underestimates $\mathrm{NmF} 2$ values during 00-07 and 21-24 LT in the nighttime for all seasons, and overestimates $\mathrm{NmF} 2$ values from 08 to $20 \mathrm{LT}$ in the daytime for all seasons. Therefore, the empirical ionospheric model, IRI-2001, cannot accurately predict the region variation of the ionosphere over South Korea, and local observation data are required to study the ionospheric parameters and their variations. In the following, the TEC, NmF2 and EST and their seasonal variations are investigated using GPS and ionosonde a priori observations in South Korea. Fig. 2 shows the diurnal behavior of the seasonal median of the TEC averaged over three months (season). A significant diurnal variation is observed for all seasons. The maximum TEC values arrive at about noon, between 11 and $14 \mathrm{LT}$. In addition, the larger TEC values are observed during equinoxes (spring equinox especially). The so-called winter anomaly that the daytime TEC value tends to be greater in winter than in summer is observed over Anyang station from around 10-12 LT, because TEC values corresponding to winter (DJF) are slightly greater (about 5-16\%) than those of summer (JJA). However, the nighttime behavior shows that TEC values are higher in summer than in winter, which indicates that this phenomenon vanishes at night near the moderate solar activity in 2003. In

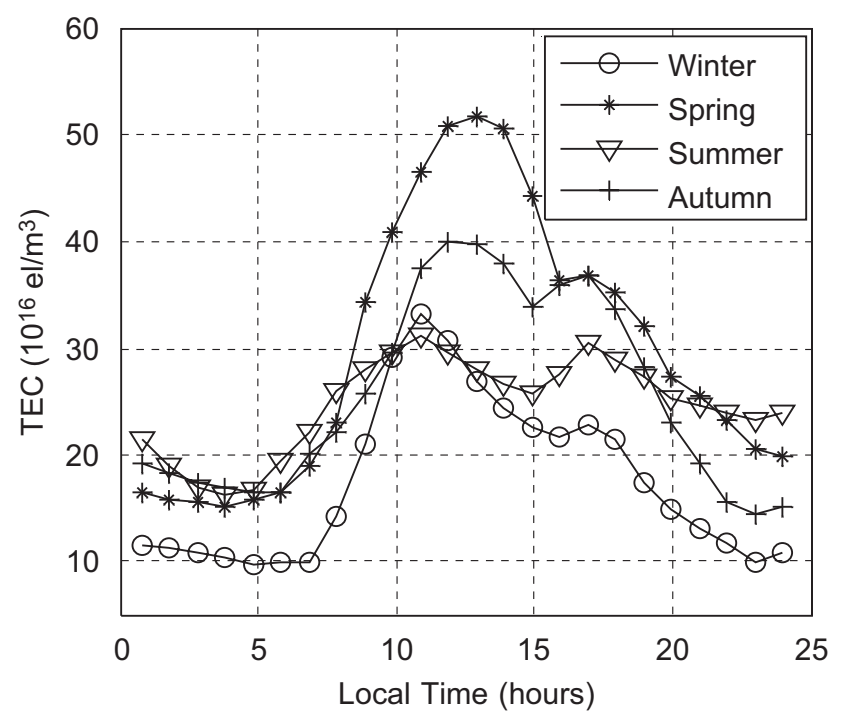

Fig. 2. Averaged diurnal variations of the seasonal median of the TEC.
Table 1

Average diurnal ratio of parameters from GPS measurements over Anyang station

\begin{tabular}{lllll}
\hline Ratio $^{\text {a }}$ & Winter & Spring & Summer & Autumn \\
\hline TEC ratios & 3.3 & 3.5 & 1.7 & 2.8 \\
NmF2 ratios & 3.4 & 2.4 & 1.5 & 2.2 \\
EST ratios & 1.6 & 1.8 & 1.9 & 1.6 \\
\hline
\end{tabular}

${ }^{\mathrm{a}}$ The diurnal ratio is defined as the ratio of maximum value to minimum one.

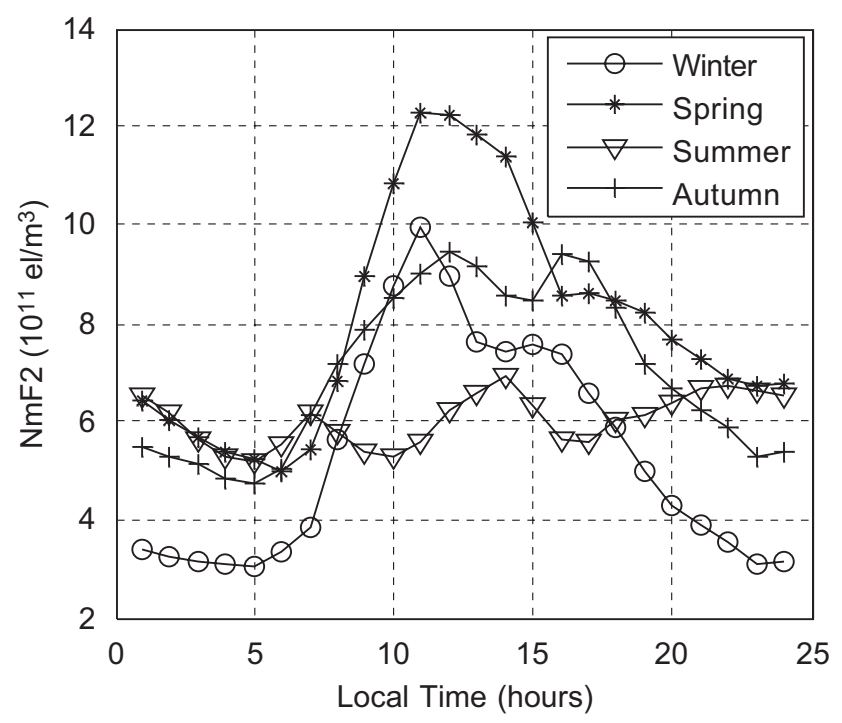

Fig. 3. Averaged diurnal variations of the seasonal median of the maximum electron density $\mathrm{NmF} 2$.

addition, the diurnal ratio, as defined by the ratio of daytime maximum TEC to the nighttime minimum TEC (Essex, 1978), is further compared (Table 1). It has been shown that the variation ratio of TEC is smaller in summer and larger in spring.

Fig. 3 presents the averaged diurnal variation of $\mathrm{NmF} 2$ from GPS tomography reconstruction for four seasons as in Fig. 1. As in TEC values, greater $\mathrm{NmF} 2$ are observed during the equinoxes (the socalled semiannual anomaly). This semiannual anomaly is also supported by the $\mathrm{NmF} 2$ ratios (in Table 1). The NmF2 is higher in winter than in summer from 08 to $18 \mathrm{LT}$ in daytime (about $50 \%$ at $11 \mathrm{LT}$ ), while the NmF2 is opposite during $00-08$ and $18-24 \mathrm{LT}$ in nighttime. It indicates the existence of the winter NmF2 anomaly over Anyang station in 2003. It is well known that in $F$ region the loss rate of electron density depends mainly on the molecular nitrogen concentration $\left[\mathrm{N}_{2}\right]$, with some contribution from molecular oxygen concentration 
$\left[\mathrm{O}_{2}\right]$, while the production rate depends on the atomic oxygen concentration [O]. The composition changes are able to sufficiently explain the equinox anomaly effect of the electron density during the daytime. These composition changes can be a result of the asymmetric heating of the two hemispheres, leading to neutral parameters being transported from the summer to the winter hemisphere. It was suggested that the winter anomaly is due to an increase in the $[\mathrm{O}] /\left[\mathrm{N}_{2}\right]$ ratio caused by the convection of atomic oxygen from the summer to the winter hemisphere (Torr and Torr, 1973). This is supported by the fact that the $[\mathrm{O}] /\left[\mathrm{N}_{2}\right]$ ratio is 2.3 times larger in winter than in summer (Cox and Evans, 1970). In addition, Torr and Torr (1973) also suggested that the semiannual anomaly is due to the semiannual variations in neutral densities associated with geomagnetic and auroral activity. Millward et al. (1996), using the coupled thermosphere-ionosphere-plasmasphere (CTIP) model, showed that the offset of the geomagnetic axis from Earth's spin axis is the cause of the semiannual anomaly of noontime NmF2 in the South American sector.

Using Eq. (2), the EST was determined from the GPS-derived TEC and NmF2. Fig. 4 shows the corresponding diurnal variation of EST in four seasons. An oscillating hourly variability is observed. A clear diurnal variation as well as considerable variability is observed. The large scatter at any fixed local time shows the importance of significant day-to-day variability of values

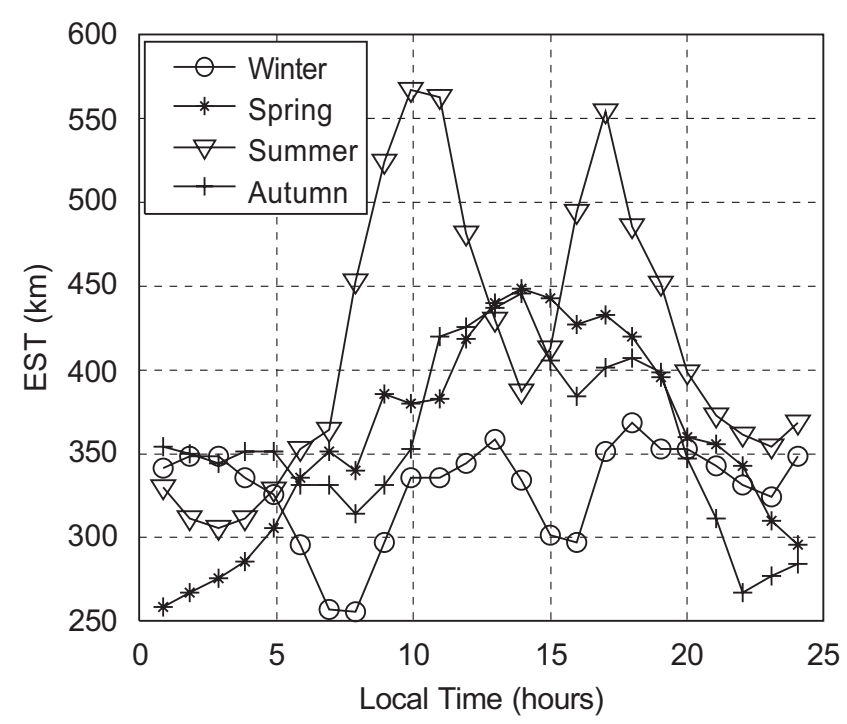

Fig. 4. Averaged diurnal variations of the seasonal median of the equivalent slab thickness (EST). between 250 and $580 \mathrm{~km}$. It can also be noted that the daytime (07-20 LT) EST shows seasonal variations, with higher values during summer and equinox as compared to the winter, and their magnitude of diurnal variation is also reflected by the EST ratio in Table 1. In addition, the nighttime (00-07 and 20-24 LT) values, however, do not show significant seasonal variations. During 07-20 LT in daytime, in general the larger EST values are observed in summer while the smaller ones are observed in winter, and the lower values for all seasons are observed during $0-07$ and $20-24$ LT in nighttime. The EST is significantly smaller in winter than in summer, but with a consistent variation pattern. During 13-16 LT, in general the larger EST values are observed in spring and autumn while the smaller ones are observed in summer and winter. In addition, two peaks appear to dominate the EST diurnal variation around $10-18 \mathrm{LT}$, especially strong dual peaks in summer. The first peak is around 10-14 LT (pre/postnoon) and the second peak is around 17-18 LT (postsunset). The pre/ postnoon increase in the EST values observed during the different seasons may be due to the downward movement of the ionosphere when the neutral winds change (Titheridge, 1973). The postsunset enhancement in the EST values could be primarily due to the field-aligned plasma flow from the protonosphere to the ionosphere and the secondary fountain effect caused by the postsunset occurrence of a strong eastward electric field existing over the equatorial latitudes (Bhuyan et al., 1986; Balan and Bailey, 1995). The whole phenomenon is mainly due to the electrodynamics of the F-region. It is known that the shape factor is most sensitive to the variations of $\mathrm{H}+/ \mathrm{O}+$ ratio at the $\mathrm{F} 2$ peak or equivalent to the transition level at which $[\mathrm{O}+]=[\mathrm{H}+]$ (Davies et al., 1976). Large downward fluxes of $\mathrm{H}+$ can decrease the $\mathrm{O}+$ to $\mathrm{H}+$ transition levels, thereby increasing the topside content and hence the slab thickness. In addition, the EST is the ratio of TEC to NmF2. Its variability is subject to the combined effect of the variabilities of both parameters simultaneously. Moreover, the EST variations are quite complex due to relating to the solar and geomagnetic activities and the latitude, etc. (Kersley and Hajeb Hosseinieh, 1976; Davies and Liu, 1991). Also, the EST variability has single day anomalies, day-to-day fluctuations and long-term periodicities of one month or more (Bhuyan et al., 1986). Therefore, the EST peak feature needs further investigation with more long 
observations in the future at different locations and solar activity conditions.

In addition, the EST is relatively lower during 00-07 and 20-24 LT in nighttime, but there is an enhancement in winter (at about 03 LT), which may be due to descending (Titheridge, 1973) of the $\mathrm{O}^{+} / \mathrm{H}^{+}$transition height (between the ionosphere and the protonosphere) in winter. This transition height can descend to as low as $250 \mathrm{~km}$ near early morning in winter. The scale height (inversely proportional to atmospheric molecular weight) is greater above the $\mathrm{O}^{+} / \mathrm{H}^{+}$transition height. It follows then that the penetration of the $\mathrm{O}^{+} / \mathrm{H}^{+}$ transition height descends more into the ionosphere, the greater the average ionospheric scale height, and hence the greater the slab thickness (which is directly proportional to the scale height).

\section{Conclusion}

The ionospheric slab thickness has a great influence on the shape of the ionospheric electron density profile $\mathrm{Ne}(h)$, and is also a convenient oneparameter summary of the electron density profile that may be related to the various physical processes. In this paper, the EST and its seasonal variability are studied with the GPS and ionosonde a priori observations in South Korea. The TEC, $\mathrm{NmF} 2$ and EST are extracted from ground-based GPS measurements in 2003, and the averaged diurnal values of the seasonal median of December-January-February (DJF), March-April-May (MAM), June-July-August (JJA) and SeptemberOctober-November (SON) in 2003 have been considered to represent the winter, spring, summer and autumn seasons, respectively. It has been shown that the systematic diurnal changes of TEC, NmF2 and EST significantly appeared in all seasons and the higher values of TEC and NmF2 were observed during the equinoxes (semiannual anomaly) as well as in mid-daytime. The EST is significantly smaller in winter than in summer, but with a consistent variation pattern. During 14-16 LT in daytime, in general the larger EST values are observed in spring and autumn while the smaller ones are observed in summer and winter. In addition, the two peaks of the EST diurnal variation obviously appeared around $10-18 \mathrm{LT}$, especially in summer. It is possibly related closely to the action of the thermospheric wind and the plasmaspheric flow in the F2region, which results in the recombination to produce a two-hump peak.

\section{Acknowledgements}

We are grateful to the National Geographic Information Institute (NGII), Ministry of Government Administration and Home Affairs (MOGAHA) and other members who made the observation GPS and ionosonde data available. This work was supported by the Korea Meteorological Administration Research and Development Program under Grant CATER 2006-3104.

\section{References}

Balan, N., Bailey, G.J., 1995. Equatorial plasma fountain and its effects: possibility of additional layer. Journal of Geophysical Research 100, 21421-21432.

Bhonsle, R.V., Da Rosa, A.V., Garriott, O.K., 1965. Measurement of total electron content and the equivalent slab thickness of the mid latitude ionosphere. Radio Science 69 (7), 929-939.

Bhuyan, P.K., Lakha, S., Tyagi, T.R., 1986. Equivalent slab thickness of the ionosphere over 26_N through the ascending half of a solar cycle. Annales Geophysicae 4, 131-136.

Bilitza, D., 2001. International reference ionosphere 2000. Radio Sciences 36, 261-275.

Cox, L.P., Evans, J.V., 1970. Seasonal variation of the O/N2 ratio in the F1 region. Journal of Geophysical Research 75, 6271-6286.

Davies, K., Liu, X.M., 1991. Ionospheric slab thickness in middle and low-latitudes. Radio Science 26, 997-1005.

Davies, K., Fritz, R.B., Gray, T.B., 1976. Measurement of columnar electron contents of the ionosphere and plasmasphere. Journal of Geophysical Research 81, 2825-2834.

Essex, E.A., 1978. Ionospheric total electron content at Southern midlatitude during 1971-1974. Journal of Atmospheric and Terrestrial Physics 40, 1019-1024.

Furman, D.R., Prasad, S.S., 1973. Ionospheric slab thickness; its relation to temperature and dynamics. Journal of Geophysical Research 78 (25), 5837-5843.

Gordon, R., Bender, R., Therman, G., 1970. Algebraic Reconstruction Techniques (ART) for three Dimensional Electron Micoscopy and X-ray Photography. Journal of Theoretical Biology 29, 471-481.

Gulyaeva, T.L., 1997. TEC residual slab thickness between bottomside and topside ionosphere. Acta Geodynamics Geophysics Hungary 32 (3-4), 355-363.

Huang, Y.N., 1983. Some result of ionospheric slab thickness observations at Lunping. Journal of Geophysical Research 88, 5517-5522.

Jaychandran, B., Krishnankutty, T., Gulyaeva, T., 2004. Climatology of ionospheric slab thickness. Annales Geophysicae 22, 25-33.

Jin, S.G., Park, J.U., 2007. GPS ionospheric tomography: A comparison with the IRI-2001 model over South Korea. Earth Planets and Space 59 (4), 287-292.

Jin, S.G., Park, J.U., Wang, J., Choi, B.K., Park, P.H., 2006. Electron density profiles derived from ground-based GPS observations. Journal of Navigation 59 (3), 395-401. 
Kersley, L., Hajeb Hosseinieh, H., 1976. Dependence of ionospheric slab thickness on geomagnetic activity. Journal of Atmospheric and Terrestrial Physics 38, 1357-1360.

Mansilla, G., Mosert, M., Ezquer, R., 2005. Variation of the total electron content, maximum electron density and equivalent slab thickness at a South-American station. Journal of Atmospheric and Solar-Terrestrial Physics 67, 1687-1690.

Millward, G.H., Rishbeth, H., Fuller-Rowell, T.J., Aylward, A.D., Quegan, S., Moffett, R.J., 1996. Ionospheric F2-layer seasonal and semiannual variations. Journal of Geophysical Research 101, 5149-5156.

Minakoshi, H., Nishimuta, I., 1994. Ionospheric electron content and equivalent slab thickness at lower mid-latitudes in the Japanese zone. Proceedings of the IBSS, University of Wales, UK, 144pp.
Pandey, V.K., Sethi, N.K., Mahajan, K.K., 2001. Equivalent slab thickness and its variability: a study with incoherent scatter measurements. Advances in Space Research 27, 61-64.

Raymund, T.D., Austen, J.R., Franke, S.J., 1990. Application of computerized tomography to the investigation of ionospheric structures. Radio Science 25, 771-789.

Titheridge, J.E., 1973. The slab thickness of the midlatitude ionosphere. Planetary Space Science 21 (10), 1775-1793.

Torr, M.R., Torr, D.G., 1973. The seasonal behaviour of the F2layer of the ionosphere. Journal of Atmospheric and Terrestrial Physics 35, 2237-2251.

Wright, J.W., 1960. A model of the F-region above hmaxF2. Journal of Geophysical Research 65, 185-191. 